\title{
Achieving the protection of high peak bone mass
}

\author{
R. P. Heaney ${ }^{1}$
}

Received: 14 December 2015 / Accepted: 16 December 2015 / Published online: 5 January 2016

(C) International Osteoporosis Foundation and National Osteoporosis Foundation 2015

Sixteen years ago, the National Osteoporosis Foundation (NOF) published a review of peak bone mass and of the factors that influence it [1]. In the ensuing years, literally hundreds of studies have been published on the topics of peak bone mass, its timing, and its contributing factors. A recent article in this journal contains the results of NOF's effort at bringing that earlier review up-to-date [2].

It is useful to recall, in 2016, that both the current and the earlier reviews were based on two premises: (1) other things being equal, a more massive bone is structurally stronger than a more flimsy bone; and (2) bone mass in the adult years is influenced by how much bone an individual has been able to acquire during growth. This accumulated mass is designated "peak" because it is the highest value an individual will normally accumulate over the course of his or her life. Put together, these premises postulate that going into the adult years having a greater bone mass provides useful protection from late life fragility fractures. It is the conjunction of these two premises that undergirds the concern about maximizing bone mass during growth.

An unexamined presumption in both reviews (and in many of the research studies they summarize) is that bone mineral density (BMD), as measured by dual energy absorptiometry (DXA), adequately captures the amount of bone (i.e., bone mass) an individual has. Ac-

R. P. Heaney

rheaney@creighton.edu

1 Creighton University, Omaha, NE, USA cordingly, measured peak BMD is commonly treated as effectively equivalent to peak bone mass. As a moment's reflection will suffice to show, and as has been pointed out elsewhere [3], that presumption is incorrect. Density is not mass, but is, rather, mass per unit volume [or, with DXA, mass per unit area of the X-Ray shadow cast by the bone(s) being measured]. It is true that measured values for mass and density are often positively correlated. But that is hardly surprising, as mass is formally incorporated into the definition and measurement of density (i.e., see above). But correlation does not establish identity.

It is important to make this distinction, as bone growth during maturation involves both accumulations of bone mass and expansion of bone volume [3, 4], two processes not always occurring in parallel. Thus, density can appear to decrease during some phases of growth at the same time as mass is increasing $[3,4]$. Clark and colleagues [5, 6], cited in the current review, are careful to dissect apart the components of BMD prior to searching for correlations with putative causes. Not all authors have been so careful.

Of more than passing interest today is how little the principal factors currently identified as influencing accumulation of a high peak bone mass have changed from the earlier synthesis [1], i.e., nutrition and mechanical loading (exercise). So, what then is the appropriate action outcome going forward? What is to be done? In asking ourselves this question, we are forced to confront yet another poorly examined presumption. Both the reviewers and the investigators whose work they review assume that public policy is science-driven. If policy remains unchanged, then perhaps it is because the science is not convincing enough. And the solution for that, obviously, is more research. 
However, a strong case can, in fact, be made that it is not science, but socio-political and economic forces, that drive nutritional policy, with science playing at best either a supporting role or an occasionally destabilizing one [when research undercuts entrenched policy [7]]. A recommendation supporting accumulation of high peak bone mass must confront school budgets that eliminate physical education, plus the endless tweaking of federal school meal programs which, in their dairy component, provide virtually the only bone-building nutrients in the daily diet of many schoolchildren. More nutritional research - unquestionably important in its own right-will not fix those problems. Nor does the importance of nutrients and exercise need much further documenting if they are to form the basis for a strategy to maximize peak bone mass in a given population. What is needed instead is advocacy - either by individuals or even by organizations such as the NOF itself. Advocacy can be a two-edged sword; it is often an uncomfortable weapon in a scientist's hands but can be powerful when wielded carefully. A good example of both edges of this sword is provided by the sodium wars [8-10], which, though beyond the scope of this editorial, nevertheless illustrate clearly both the power of advocacy to influence policy and the disarray and apparent controversy that arise when the scientific facts are found discordant with prevailing health policy [7]. In conclusion, it is worth stressing, going forward, that the premise that a high peak mass is protective remains sound and should, indeed, guide health policy. The "How?" remains an open question

\section{References}

1. Heaney RP, Abrams S, Dawson-Hughes B, Looker A, Marcus R, Matkovic V, Weaver CM (2000) Peak bone mass. Osteoporos Int 11:985-1009

2. Weaver CM, Gordon CM, Janz KF, Kalkwarf HJ, Lappe JM, Lewis R, O'Karma M, Wallace TC, Zemel BS (2016) The National Osteoporosis Foundation's position statement on peak bone mass development and lifestyle factors: a systematic review and implementation recommendations. Osteoporos Int. doi:10.1007/s00198015-3440-3

3. Matkovic V, Jelic T, Wardlaw GM, Ilich JZ, Goel PK, Wright JK, Andon MB, Smith KT, Heaney RP (1994) Timing of peak bone mass in Caucasian females and its implication for the prevention of osteoporosis. J Clin Invest 93:799-808

4. Heaney RP, Davies KM (2011) Bone mineral density discordance and exploration of one of its causes. J Clin Densitom 14(4):428-433

5. Clark EM, Ness AR, Bishop NJ, Tobias JH (2006) Association between bone mass and fractures in children: a prospective cohort study. J Bone Miner Res 21:1489-1495

6. Clark EM, Ness AR, Tobias JH (2008) Vigorous physical activity increases fracture risk in children irrespective of bone mass: a prospective study of the independent risk factors for fractures in healthy children. J Bone Miner Res 23:1012-1022

7. Miller SA, Quoted in Taubes, G (1998) The political science of salt. Science 281:898-907, Salt and Public Health

8. Bayer R, Johns DM, Galea S (2012) Contested science and the challenge of evidence-based decision making. Health Aff 31 : 2738-2746

9. Alderman MH, Cohen HW (2012) Dietary sodium intake and cardiovascular mortality: controversy resolved? Am J hypertension

10. Graudal N, Jurgens G, Baslund B, Alderman MH (2014) Compared with usual sodium intake, low- and excessive-sodium diets are associated with increased mortality: a meta-analysis. Am J Hypertension 